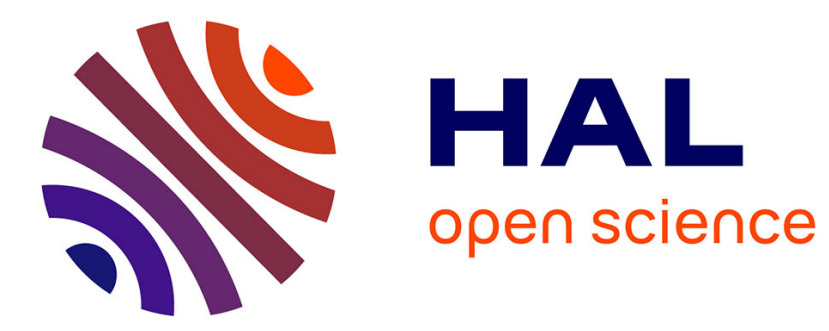

\title{
Co-oxidation kinetic model for the thermal oxidation of polyethylene-unsaturated substrate systems
}

\author{
Emmanuel Richaud, Bruno Fayolle, Jacques Verdu, Jozef Rychlý
}

\section{To cite this version:}

Emmanuel Richaud, Bruno Fayolle, Jacques Verdu, Jozef Rychlý. Co-oxidation kinetic model for the thermal oxidation of polyethylene-unsaturated substrate systems. Polymer Degradation and Stability, 2013, 98, pp.1081-1088. 10.1016/j.polymdegradstab.2013.01.008 . hal-00996704

\section{HAL Id: hal-00996704 https://hal.science/hal-00996704}

Submitted on 26 May 2014

HAL is a multi-disciplinary open access archive for the deposit and dissemination of scientific research documents, whether they are published or not. The documents may come from teaching and research institutions in France or abroad, or from public or private research centers.
L'archive ouverte pluridisciplinaire HAL, est destinée au dépôt et à la diffusion de documents scientifiques de niveau recherche, publiés ou non, émanant des établissements d'enseignement et de recherche français ou étrangers, des laboratoires publics ou privés. 


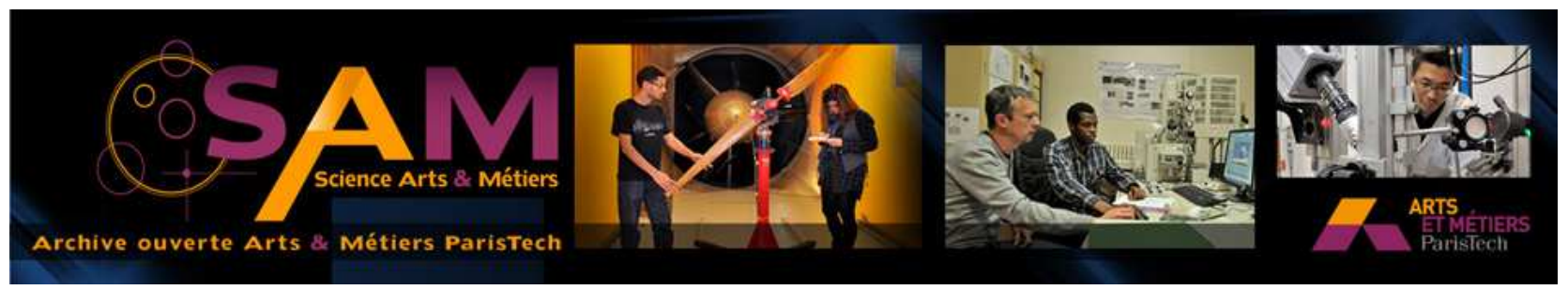

Science Arts \& Métiers (SAM)

is an open access repository that collects the work of Arts et Métiers ParisTech researchers and makes it freely available over the web where possible.

This is an author-deposited version published in: http://sam.ensam.eu

Handle ID: .http://hdl.handle.net/10985/8197

\section{To cite this version :}

Emmanuel RICHAUD, Bruno FAYOLLE, Jacques VERDU, Jozef RYCHLÝ - Co-oxidation kinetic model for the thermal oxidation of polyethylene-unsaturated substrate systems - Polymer Degradation and Stability - Vol. 98, p.1081-1088 - 2013 


\title{
Co-oxidation kinetic model for the thermal oxidation of polyethylene-unsaturated substrate systems
}

\author{
Emmanuel Richaud ${ }^{\mathrm{a}, *}$, Bruno Fayolle ${ }^{\mathrm{a}}$, Jacques Verdu ${ }^{\mathrm{a}}$, Jozef Rychlý ${ }^{\mathrm{b}}$ \\ a Arts et Metiers ParisTech, CNRS, PIMM UMR 8006, 151 bd de l'Hôpital, 75013 Paris, France \\ b Polymer Institute, Slovak Academy of Sciences, Dúbravská cesta 11, 84236 Bratislava, Slovak Republic
}

Keywords:

Polyethylene

Methyl esters of unsaturated fatty acids

Co-oxidation

Kinetic modeling

Chemiluminescence

\begin{abstract}
A B S T R A C T
The thermal oxidation of polyethylene (PE) impregnated by the methyl esters of unsaturated fatty acids (UFEs) was studied using chemiluminescence, and infra-red spectrophotometry. It was shown that the presence of UFEs accelerates the PE aging process. This can be interpreted as a co-oxidation phenomenon. In this study, the previously established models for PE and UFEs self-oxidation have been coupled in order to develop a co-oxidation model. Using the existing rate constants for the PE and UFEs selfoxidations, this model can simulate the complex shape of the kinetic curves of PE-UFE co-oxidation.
\end{abstract}

\section{Introduction}

In a first approach, the oxidation mechanism at relatively moderate temperatures $\left(<150^{\circ} \mathrm{C}\right)$ of a hydrocarbon substrate with a single reactive site, when there is an oxygen excess (that is when there is no contribution of alkyl radicals $\mathrm{P}^{\circ}$ to the termination reactions) can be depicted by the following scheme [1,2]:

(Ib) $\mathrm{ROOH}+\mathrm{ROOH} \rightarrow \mathrm{R}^{\circ}+\mathrm{ROO}^{\circ}+$ carbonyls + scissions $\mathrm{k}_{1 \mathrm{~b}}$

(II) $\mathrm{R}^{\circ}+\mathrm{O}_{2} \rightarrow \mathrm{ROO}^{\circ} \quad \mathrm{k}_{2}$

(III) $\mathrm{ROO}^{\circ}+\mathrm{RH} \rightarrow \mathrm{ROOH}+\mathrm{R}^{\circ}$

(VI) $\mathrm{ROO}^{\circ}+\mathrm{ROO}^{\circ} \rightarrow$ inactive products

Over the years, this model as well as several completed versions has been developed with a view to describing the oxidation of substrates under specific reaction conditions, namely, when it can be assumed that there is only one kind of reactive site which corresponds to the weakest $\mathrm{C}-\mathrm{H}$ bond and the highest propagation rate constant $\mathrm{k}_{3}$ [3]. Some examples are: tertiary carbons in polypropylene [4], secondary carbons in polyethylene [5] and allylic ones in butadiene rubber [6].

\footnotetext{
* Corresponding author. Tel.: +33 144246316.

E-mail address: emmanuel.richaud@ensam.eu (E. Richaud).
}

It is well documented that oxidation can be favored by metallic impurities playing a catalytic (redox) role [7] or by species such as carboxylic acids capable of establishing strong hydrogen bonds with the polymeric ROOH groups [8]. These cases of assisted oxidation differ from the co-oxidation phenomena described in this current study. Here, the simultaneous in chain oxidation of two different kinds of reactive sites corresponding to two categories of $\mathrm{C}-\mathrm{H}$ groups will be studied.

In such a case of co-oxidation, Decker et al. [9] showed that the oxidizability of ethylene propylene copolymer varies with the ethylene molar fraction $e$ according to a pseudo-hyperbolic curve which can be approximated by the following function:

$\frac{\mathrm{k}_{3}}{\sqrt{\mathrm{k}_{6}}}=10^{-4} \times \frac{2-1.63 \times e}{1+3.13 \times e}$

here $\mathrm{k}_{3}$ and $\mathrm{k}_{6}$ can be defined as the rate constants characteristic of a virtual homopolymer which would exhibit the same kinetic behavior as the copolymer under study. In fact, an approach in which the kinetic behavior of the copolymer could be predicted from the characteristics of the corresponding homopolymers would be far more satisfactory. In the case of propagation, the presence of two reactive sites needs to take into account four elementary reactions: 


$$
\begin{array}{lll}
(\mathrm{III}-11) & \mathrm{R}_{1} \mathrm{OO}^{\circ}+\mathrm{R}_{1} \mathrm{H} \rightarrow \mathrm{R}_{1} \mathrm{OOH}+\mathrm{R}_{1} & \mathrm{k}_{311} \\
(\mathrm{III}-12) & \mathrm{R}_{1} \mathrm{OO}^{\circ}+\mathrm{R}_{2} \mathrm{H} \rightarrow \mathrm{R}_{1} \mathrm{OOH}+\mathrm{R}_{2^{\circ}} & \mathrm{k}_{312} \\
(\mathrm{III}-21) & \mathrm{R}_{2} \mathrm{OO}^{\circ}+\mathrm{R}_{1} \mathrm{H} \rightarrow \mathrm{R}_{2} \mathrm{OOH}+\mathrm{R}_{1^{\circ}} & \mathrm{k}_{321} \\
(\mathrm{III}-22) & \mathrm{R}_{2} \mathrm{OO}^{\circ}+\mathrm{R}_{2} \mathrm{H} \rightarrow \mathrm{R}_{2} \mathrm{OOH}+\mathrm{R}_{2^{\circ}} & \mathrm{k}_{322}
\end{array}
$$

In the case of termination, one cross termination must be added to the two self-terminations:

$$
\begin{array}{lll}
(\mathrm{VI}-11) & \mathrm{R}_{1} \mathrm{OO}^{\circ}+\mathrm{R}_{1} \mathrm{OO}^{\circ} \rightarrow \text { inactive product }+\mathrm{O}_{2} & \mathrm{k}_{611} \\
(\mathrm{VI}-12) & \mathrm{R}_{1} \mathrm{OO}^{\circ}+\mathrm{R}_{2} \mathrm{OO}^{\circ} \rightarrow \text { inactive product }+\mathrm{O}_{2} & \mathrm{k}_{612} \\
(\mathrm{VI}-22) & \mathrm{R}_{2} \mathrm{OO}^{\circ}+\mathrm{R}_{2} \mathrm{OO}^{\circ} \rightarrow \text { inactive product }+\mathrm{O}_{2} & \mathrm{k}_{622}
\end{array}
$$

Russell [10] proposed the following expression for the oxidation rate:

$$
r_{\mathrm{OX}}=\frac{\frac{\mathrm{k}_{311}}{\mathrm{k}_{322}}\left[\mathrm{R}_{1} \mathrm{H}\right]^{2}+2\left[\mathrm{R}_{1} \mathrm{H}\right]\left[\mathrm{R}_{2} \mathrm{H}\right]+\frac{\mathrm{k}_{322}}{\mathrm{k}_{321}}\left[\mathrm{R}_{2} \mathrm{H}\right]^{2}}{\sqrt{\frac{2 \mathrm{k}_{611}}{\mathrm{k}_{312}^{2}}\left[\mathrm{R}_{1} \mathrm{H}\right]^{2}+\frac{2 \mathrm{k}_{612}}{\mathrm{k}_{321} \cdot \mathrm{k}_{321}} \cdot\left[\mathrm{R}_{1} \mathrm{H}\right]\left[\mathrm{R}_{2} \mathrm{H}\right]+\frac{2 \mathrm{k}_{622}}{\mathrm{k}_{321}^{2}}\left[\mathrm{R}_{2} \mathrm{H}\right]^{2}}} \cdot \sqrt{r_{\mathrm{i}}}
$$

In it he assumed an unique initiation reaction of constant rate $r_{i}$, a steady state and long kinetic chains. Apart from those two pioneering works, little has been done on co-oxidation mechanisms either from the experimental [11] or from a modeling approach [12]. This is in spite of the fact that solving the complex differential systems derived from the co-oxidation scheme is nowadays relatively easy thanks to numerical solvers.

In this paper, we introduce a co-oxidation model for PE + the methyl esters of unsaturated fatty acids (UFEs) from vegetable sources. There is a need for such a model because:

- UFEs are the main components of biodiesels obtained from vegetable sources. Since these will come into contact with the polyethylene parts of automotive engines such as tanks [13] (if they are not protected by physical barriers such as fluorinated polymers). The question arises do the UFEs interact with the PE oxidative aging process to the detriment of the polymer durability? This problem, which is becoming increasingly important, has received little attention until now.

- From a theoretical point of view, the UFEs system appears interesting owing to the clear difference in the oxidizabilities of PE and the UFEs it can be impregnated with (holding either 1,2 or 3 double bonds). The oxidation of each individual substrate PE, methyl oleate, methyl linoleate and methyl linolenate) have all been previously studied [5,14]. Hence, PE + UFE mixtures are ideal systems for the study of cooxidation kinetics.

One criticism regarding the development of a possible kinetic model is the elevated number of rate constants being a priori adjustable parameters permitting to fit any experimental results. Here, any model proposed should meet three requirements:

(1) It must simulate the relatively most complex shape of the cooxidation curves for processes involving two substrates with different reactivities.

(2) It must involve kinetic parameters identical to those determined for modeling the oxidation of the pure polyethylene [5] as well as the pure methyl esters [14].

(3) Its heuristic properties should permit it to predict the relative contribution of each substrate to the global oxidation curves monitored by FTIR or chemiluminescence.
With this in mind, the coupled degradation of a PE-UFE series was studied using chemiluminescence at $150{ }^{\circ} \mathrm{C}$. Another solid state $\left(80^{\circ} \mathrm{C}\right)$ series was also studied in an effort to separate the PE and UFEs oxidation by-products.

\section{Experimental}

\subsection{Materials}

Polyethylene was supplied as an antioxidant free powder. This was verified by observing the absence of an induction period at $200{ }^{\circ} \mathrm{C}$. DSC analysis revealed a melting temperature of $132^{\circ} \mathrm{C}$ with a melting enthalpy close to $150 \mathrm{~J} \mathrm{~g}^{-1}$. This corresponds to a crystallinity ratio of about $50 \%$.

According to Demirbaş et al. [15], vegetable oils are mainly composed of the methyl esters of fatty acids with 16 or 18 carbons in their linear hydrocarbon chains. Two important compounds are methyl oleate and methyl linolenate which have different oxidative stabilities. Methyl oleate (ref S54470-478) and methyl linolenate (ref 62210) were supplied by Sigma Aldrich.

The impregnation of the methyl esters into the PE at various temperatures has been previously described [16]. To summarize the initial state of the materials used were: (1) pure PE, (2) PE impregnated with $5 \%$ weight methyl oleate, (3) PE impregnated with $10 \%$ weight methyl oleate and (4) PE impregnated with 5\% methyl linolenate.

\subsection{Exposure conditions}

Impregnated films were submitted to one of the two following conditions: (1) thermal aging in ovens at $80^{\circ} \mathrm{C}$ monitored by FTIR, (2) thermal aging at $150{ }^{\circ} \mathrm{C}$ under $0.1 \mathrm{MPa} \mathrm{O}_{2}$ monitored in situ by $\mathrm{CL}$.

\subsection{Characterization}

\subsubsection{Chemiluminescence}

Chemiluminescence experiments were performed using a Lumipol 3 apparatus designed in-house at the Polymer Institute in the Slovak Academy of Sciences [7]. Films impregnated by methyl oleate and linolenate were placed into aluminum pans and heated under nitrogen to $150{ }^{\circ} \mathrm{C}$. They were then maintained at this temperature under oxygen at $0.1 \mathrm{MPa}$ pressure.

\subsubsection{Extraction of the methyl esters of the unsaturated fatty acids}

After thermal oxidation of the PE impregnated by UFE, both the UFE and its oxidation by-products were extracted using $\mathrm{CH}_{2} \mathrm{Cl}_{2}$ overnight at room temperature. An example of the observed differences in the FTIR spectra between an impregnated PE sample both before and after extraction are shown in the spectra in Fig. 1 at $t=0$. These show the total UFE extraction. Those in Fig. 3 represent the samples after several exposure durations.

\subsubsection{FTIR}

FTIR spectra of the PE films were recorded in transmittance mode using a Spectrum 100 spectrophotometer (Perkin Elmer), with 4 scans at $4 \mathrm{~cm}^{-1}$ resolution. Both the virgin and oxidized methyl esters of the unsaturated fatty acids display an absorption peak at ca $1740 \mathrm{~cm}^{-1}$. After removing the UFEs and its soluble byproducts from $\mathrm{PE}$, only a peak at $1720 \mathrm{~cm}^{-1}$ remains. This is attributed to carbonyl compounds resulting from the PE oxidation. The carbonyl absorbance before and after extraction were converted into concentrations using the molar absorptivity of $3001 \mathrm{~mol}^{-1} \mathrm{~cm}^{-1}$ [17]. 


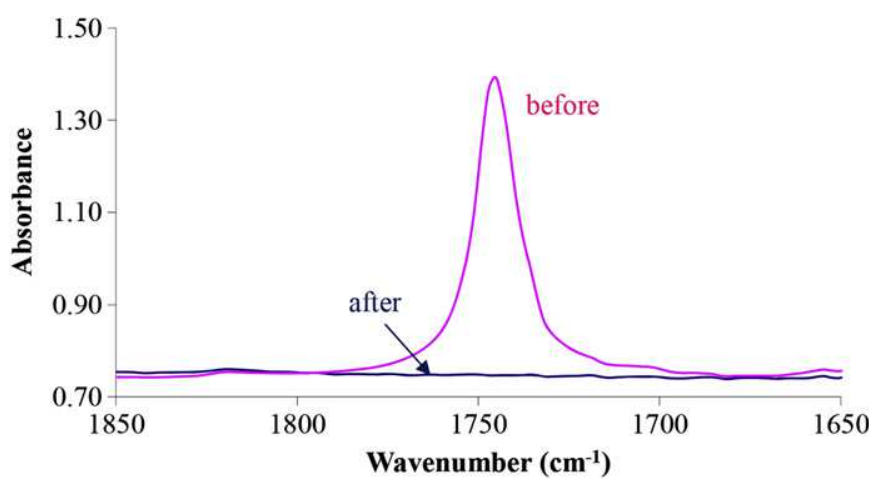

Fig. 1. FTIR spectra in the $1850-1650 \mathrm{~cm}^{1}$ wavenumber range for $\mathrm{PE}+$ methyl linolenate before and after extraction.

\section{Results}

\subsection{Chemiluminescence study}

Impregnated films were submitted to a thermo-oxidative aging procedure monitored in situ in a CL apparatus. TGA results confirmed that only a minor part of the absorbed UFE was lost by evaporation in the timescale under consideration.

Typical CL results for oxidation at $150{ }^{\circ} \mathrm{C}$ under $0.1 \mathrm{MPa} \mathrm{O}_{2}$ are shown in Fig. 2. A close examination of the results leads to the following observations:

(1) For pure PE, the curve has the classical sigmoidal shape. In addition, a small shoulder at time $\sim 10000 \mathrm{~s}$ can be seen. According to Broska [18], this could be attributed to the existence of structural irregularities in PE (such as vinyl chain ends). This interpretation is, as will be confirmed later, in good agreement with the proposed kinetic model for cooxidation involving the role of double bonds.

(2) Next, for the PE + methyl oleate, the CL kinetic curve shifts towards shorter times. This clearly suggests that the PE matrix is oxidized faster in the presence than in the absence of an UFE.

(3) The trends observed for the PE + methyl oleate are strongly exaggerated for the PE + methyl linolenate system where an intense peak was seen to develop in the early days of exposure and also where the light emission in the first $5000 \mathrm{~s}$ is considerably stronger than for the other samples.

\subsection{FTIR study}

The accelerating effect of UFE on the PE oxidation was confirmed by studying the oxidation process in the solid state. The following conclusions can be made as a result of the data shown in the FTIR spectra showing the carbonyl range for PE impregnated with ca $5 \%$ by weight of methyl linolenate (see Figs. 1 and 3). First, the absorbance at $1745 \mathrm{~cm}^{-1}$ is due to the ester group of the UFE. The absorbance at $1720 \mathrm{~cm}^{-1}$ is due to the presence of ketones and carboxylic acids resulting from the oxidation of the PE and the UFE.

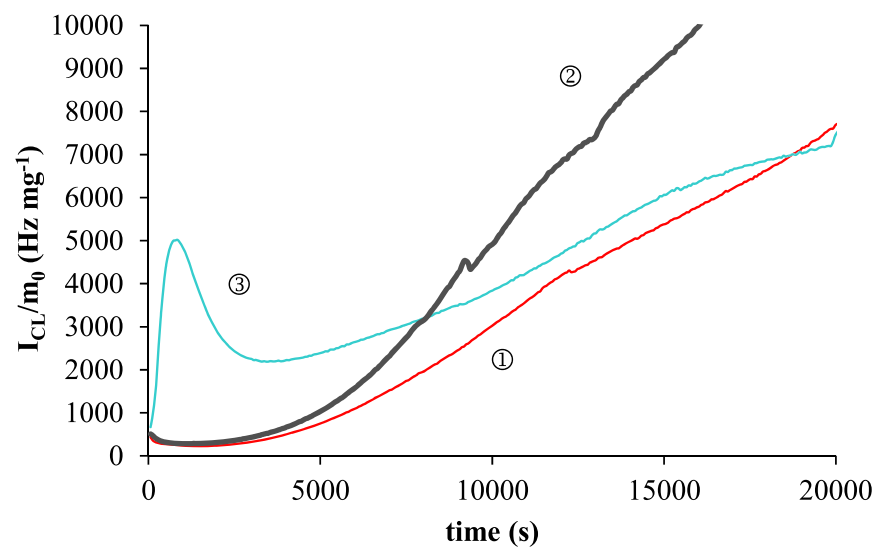

Fig. 2. Kinetic curves of chemiluminescence emission for thermal oxidation at $150{ }^{\circ} \mathrm{C}$ of pure PE (1), PE + methyl oleate (2), PE + methyl linolenate (3).

The absorbance of the impregnated samples is shifted during the first hours of exposure from 1745 to $1735 \mathrm{~cm}^{-1}$ and then towards $1720 \mathrm{~cm}^{-1}$. The former shift is a result of the UFE oxidation, whereas the PE oxidation leads to the second shift. After extraction by $\mathrm{CH}_{2} \mathrm{Cl}_{2}$, it is reasonable to assume that residual carbonyl peak centered at ca $1720 \mathrm{~cm}^{-1}$ is linked to the oxidation level of PE matrix.

The results presented in Figs. 4 and 5 show a comparison between oxidation of a pure PE film and of an UFE-impregnated one. The kinetics curves which give the carbonyl concentration in the PE matrix with an UFE after aging are shifted towards shorter times compared to the kinetic curve for pure PE. Despite a noticeable scatter, these results clearly confirm that unsaturated fatty esters accelerate the polyethylene matrix oxidation. This effect is increased with the UFE concentration in PE (Fig. 4). It can also be seen that methyl linolenate has a stronger influence than methyl oleate (Fig. 5).

\section{Discussion}

\subsection{Proposal of a mechanistic scheme}

According to Figs. 2, 4 and 5, a co-oxidation mechanism, similar to that proposed for ethylene propylene copolymers EPR [9] can be expected to occur. This would be comparable to the mechanism also proposed in the case of PP in which the participation of both secondary and tertiary carbons was demonstrated as a result of the analysis of the hydroperoxides and alcohols $[19,20]$.

The inherent nature of such a combined mechanism leads to very complex mechanistic scheme with a greater number of kinetic parameters needing to be determined [12]. It is now pertinent to elaborate a model describing the most striking experimental features with the minimum number of adjustable kinetic parameters, that is starting from the PE oxidation model [4] and the UFE one [14] together with some cross reactions and retaining the previously determined rate constant values. The following mechanistic scheme is a valid first approach: 


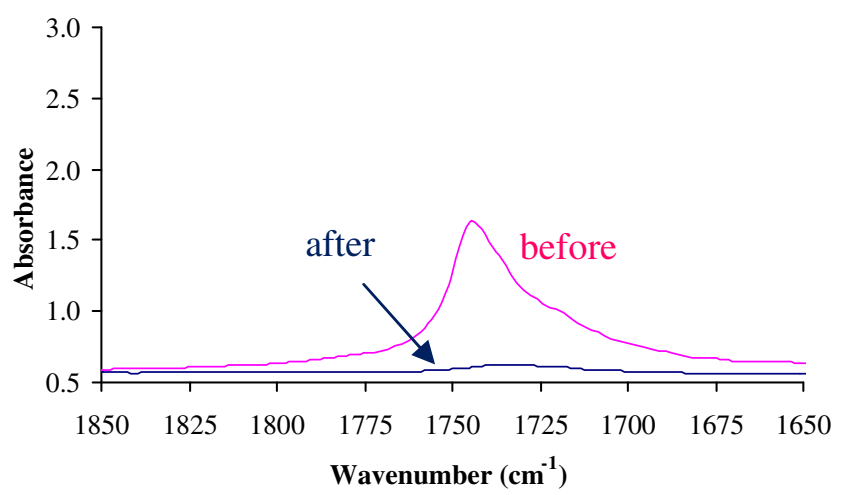

a: $48 \mathrm{~h}$

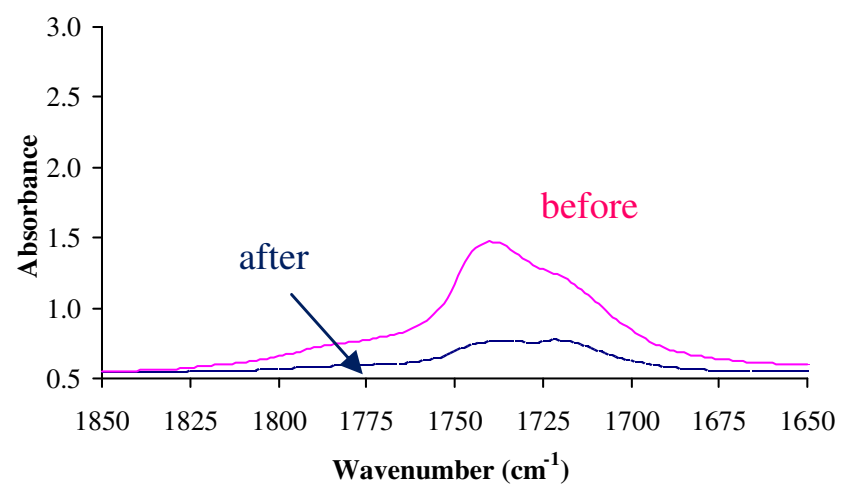

c: $500 \mathrm{~h}$

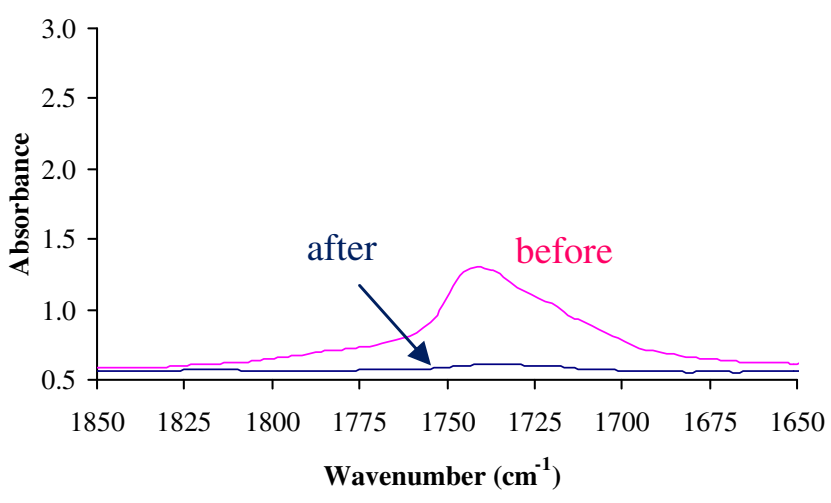

b: $212 \mathrm{~h}$

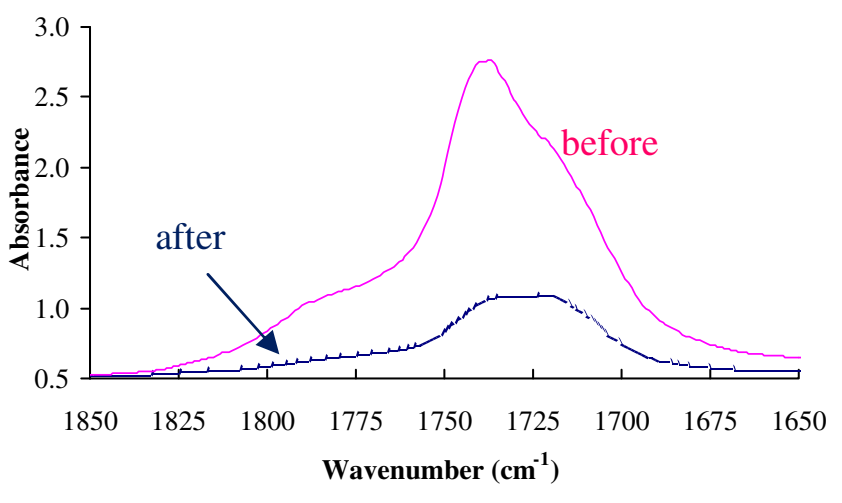

$\mathrm{d}: 825 \mathrm{~h}$

Fig. 3. FTIR spectra in the $18,501,650 \mathrm{~cm}^{1}$ wavenumber range for $\mathrm{PE}+$ methyl linolenate thermooxidized at $80{ }^{\circ} \mathrm{C}$ before and after extraction.

\begin{tabular}{|c|c|c|}
\hline (II1) & $\mathrm{UFE}^{\circ}+\mathrm{O}_{2} \rightarrow \mathrm{UFEOO}^{\circ}$ & $\mathrm{k}_{21}$ \\
\hline (II2) & $\mathrm{PE}^{\circ}+\mathrm{O}_{2} \rightarrow \mathrm{PEOO}^{\circ}$ & $\mathrm{k}_{22}$ \\
\hline (III22) & $\mathrm{PEOO}^{\circ}+\mathrm{PEH} \rightarrow \mathrm{PEOOH}+\mathrm{PE}^{\circ}$ & $\mathrm{k}_{322}$ \\
\hline (III11) & $\mathrm{UFEOO}^{\circ}+\mathrm{UFEH} \rightarrow \mathrm{UFEOOH}+\mathrm{UFE}^{\circ}$ & $\mathrm{k}_{311}$ \\
\hline (III12) & $\mathrm{UFEOO}^{\circ}+\mathrm{PEH} \rightarrow \mathrm{UFEOOH}^{\circ} \mathrm{PE}^{\circ}$ & $\mathrm{k}_{312}$ \\
\hline (III21) & $\mathrm{PEOO}^{\circ}+\mathrm{UFEH} \rightarrow \mathrm{PEOOH}+\mathrm{UFE}^{\circ}$ & $\mathrm{k}_{321}$ \\
\hline I22) & $\mathrm{PEOO}^{\circ}+\mathrm{PEOO}^{\circ} \rightarrow \mathrm{i}$ & \\
\hline & UFEOC & \\
\hline & tive produ & \\
\hline
\end{tabular}

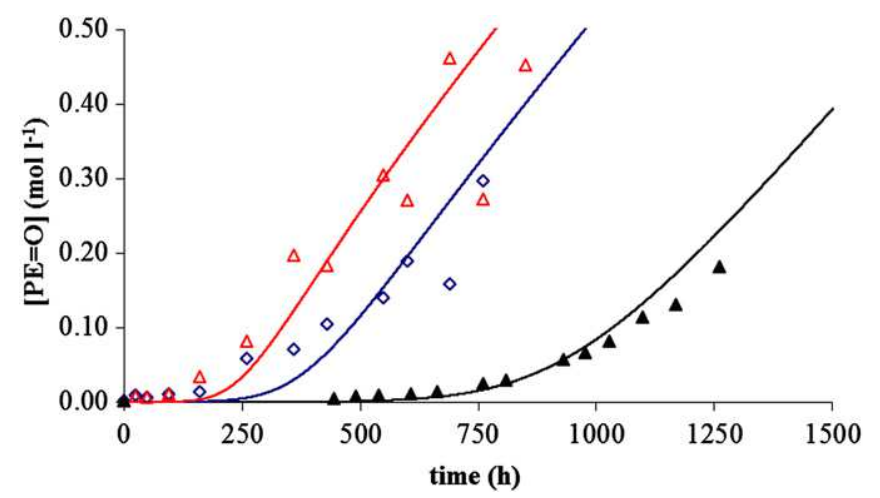

Fig. 4. Kinetic curves at $80{ }^{\circ} \mathrm{C}$ for carbonyl buildup of PE matrix for pure PE ( $\boldsymbol{\Delta}$ ), PE oxidized in presence of $5 \%(\diamond)$ and $10 \%$ methyl oleate $(\Delta)$ followed by $\mathrm{CH}_{2} \mathrm{Cl}_{2}$ extraction of UFE oxidation by-products, together with the corresponding curves generated by the kinetic model with parameters given in Tables 2 and 3 .
The cross-initiation reaction (Ib12) between $\mathrm{PEOOH}$ and $\mathrm{UFEOOH}$ is theoretically the balance between the two pathways shown below:

$$
\begin{aligned}
& -\mathrm{CH}_{2}-\mathrm{CH}-\mathrm{CH}_{2}- \\
& -\underset{\mathrm{OOH}}{\mathrm{CH}-\mathrm{CH}-\mathrm{CH}_{2}-} \\
& \text { 1. } \quad \begin{array}{c}
\mathrm{OO}^{\circ}-\mathrm{HC}=\mathrm{CH}-\mathrm{CH}-\mathrm{CH}_{2}- \\
\mathrm{O}^{\circ}
\end{array}
\end{aligned}
$$

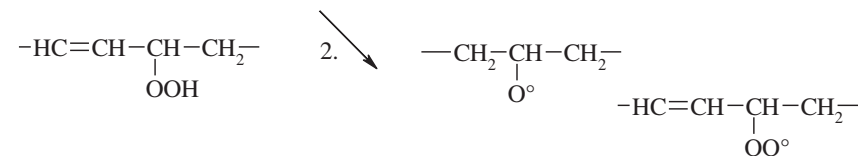

On the basis of the thermochemical considerations shown in Table 1 , the $\Delta G_{R}$ is lower for pathway 2 . It can be assumed, therefore, that the reaction between PEOOH and UFEOOH can be written as a single balance equation:

$$
(\mathrm{Ib} 12) \mathrm{UFEOOH}+\mathrm{PEOOH} \rightarrow \mathrm{PE}^{\circ}+\mathrm{UFEOO}^{\circ}+\mathrm{PE}=\mathrm{O} \quad \mathrm{k}_{\mathrm{b} 12}
$$

\subsection{Estimation of kinetic parameters for the co-oxidation model}

Oxygen solubility in impregnated polyethylene is supposed unmodified by the presence of a few \% by weight of UFE. Its value will therefore be taken equal to the value reported by Van Krevelen [21] in his monograph: $\mathrm{s}_{\mathrm{O} 2}=1.8 \times 10^{-8} \mathrm{~mol} \mathrm{l}^{-1} \mathrm{~Pa}^{-1}$.

All the kinetic parameters for polyethylene $\left(\mathrm{k}_{\mathrm{u} 2}, \mathrm{k}_{\mathrm{b} 22}, \mathrm{k}_{22}, \mathrm{k}_{322}\right.$, $\mathrm{k}_{622}$ and associated activation energies have been determined previously [5] hence will be used without change. They are shown in Table 2. For PE, $\mathrm{k}_{60}, \mathrm{k}_{61}, \mathrm{k}_{62}$ and $\mathrm{k}_{63}$ are combined to give an apparent rate constant $\mathrm{k}_{622}$ equal to: 


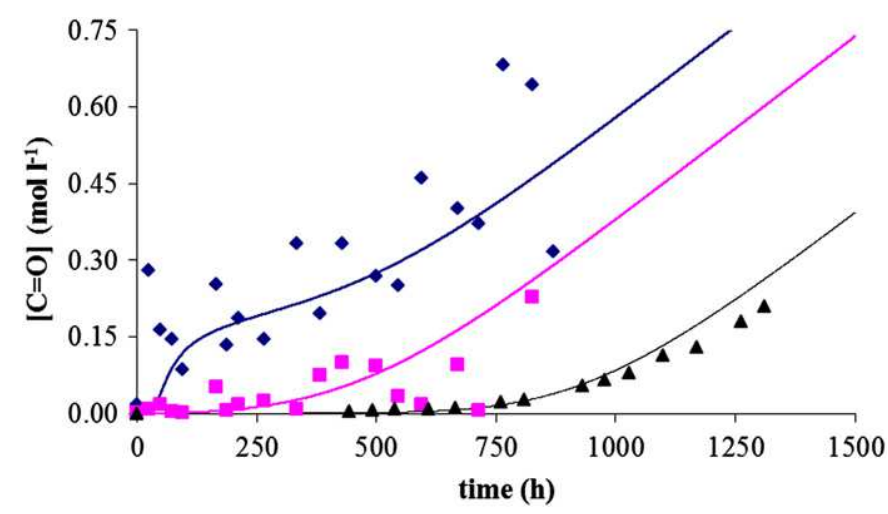

Fig. 5. Kinetic curves at $80{ }^{\circ} \mathrm{C}$ for carbonyl buildup for pure PE ( $\boldsymbol{\Lambda}$ ), total carbonyl concentration in PE impregnated by methyl linolenate $(\bullet)$, residual carbonyl in PE after removing by $\mathrm{CH}_{2} \mathrm{Cl}_{2}$ of methyl linolenate and its oxidation by-products removing (ם) together with the corresponding curves generated by the kinetic model with parameters given in Tables 2 and 3.

$\mathrm{k}_{622}=\frac{\mathrm{k}_{60}}{\left(1+\frac{\mathrm{k}_{63}}{\mathrm{k}_{61}+\mathrm{k}_{62}}\right) \cdot\left(1+\frac{\mathrm{k}_{63}}{2\left(\mathrm{k}_{61}+\mathrm{k}_{62}\right)}\right)}$

The kinetic parameters for methyl oleate and linolenate were tentatively determined and reported in a recent work based on a study of the oxidation of pure compounds monitored by CL [14].

It is now necessary to consider the cross reaction rate constants. According to Korcek's law [3], the rate constant for $\mathrm{ROO}^{\circ}+\mathrm{PH} \rightarrow \mathrm{ROOH}+\mathrm{P}^{\circ}$ depends only on the value of the bond dissociation energy. Hence it is possible to suppose:

$\mathrm{k}_{312}=\mathrm{k}_{322}$

$\mathrm{k}_{321}=\mathrm{k}_{311}$

In addition, for the initiation and termination rate constants, it will be assumed:

$\mathrm{k}_{\mathrm{b} 12}^{2}=\mathrm{k}_{\mathrm{b} 11} \times \mathrm{k}_{\mathrm{b} 22}$

$\mathrm{k}_{612}^{2}=\mathrm{k}_{611} \times \mathrm{k}_{622}$

\subsection{A comparison between model output data and} chemiluminescence results

There is a wide range of species possibly present in PE in low concentrations that may be eventually responsible for the initial
Table 2

Kinetic parameters of PE oxidation kinetic model [5].

\begin{tabular}{llll}
\hline Code & Rate constant & Pre-exponential factor & Activation energies \\
\hline $1 \mathrm{u}$ & $\mathrm{k}_{1 \mathrm{u}}$ & $8.0 \times 10^{12} \mathrm{~s}^{-1}$ & $140 \mathrm{~kJ} \mathrm{~mol}^{-1}$ \\
$1 \mathrm{~b}$ & $\mathrm{k}_{1 \mathrm{~b}}$ & $2.8 \times 10^{9} 1 \mathrm{~mol}^{-1} \mathrm{~s}^{-1}$ & $105 \mathrm{~kJ} \mathrm{~mol}^{-1}$ \\
2 & $\mathrm{k}_{2}$ & $1.0 \times 10^{8} 1 \mathrm{~mol}^{-1} \mathrm{~s}^{-1}$ & $0 \mathrm{~kJ} \mathrm{~mol}^{-1}$ \\
3 & $\mathrm{k}_{3}$ & $1.5 \times 10^{10} 1 \mathrm{~mol}^{-1} \mathrm{~s}^{-1}$ & $73 \mathrm{~kJ} \mathrm{~mol}^{-1}$ \\
60 & $\mathrm{k}_{60}$ & $4.9 \times 10^{19} 1 \mathrm{~mol}^{-1} \mathrm{~s}^{-1}$ & $80 \mathrm{~kJ} \mathrm{~mol}^{-1}$ \\
61 & $\mathrm{k}_{61}$ & $2.0 \times 10^{6} \mathrm{~s}^{-1}$ & $0 \mathrm{~kJ} \mathrm{~mol}^{-1}$ \\
62 & $\mathrm{k}_{62}$ & $1.2 \times 10^{5} \mathrm{~s}^{-1}$ & $5 \mathrm{~kJ} \mathrm{~mol}^{-1}$ \\
63 & $\mathrm{k}_{63}$ & $8.0 \times 10^{12} \mathrm{~s}^{-1}$ & $50 \mathrm{~kJ} \mathrm{~mol}^{-1}$ \\
\hline
\end{tabular}

oxidation steps. In addition to others these are peroxides, and unreacted polymerization catalysts. It is warranted to consider that initial PE contains only hydroperoxides in an initial concentration $[\mathrm{POOH}]_{0}$, the decomposition of $[\mathrm{POOH}]_{0}$ yielding to the same quantity of radicals than the overall unstable species initially present. Since $\mathrm{POOH}$ groups accumulate during oxidation while other eventually unstable species are consumed, the $\mathrm{POOH}$ decomposition rapidly becomes the largely predominant initiation process and this in fact justifies the mechanistic scheme chosen [22]. It was assumed that $[\mathrm{PEOOH}]_{0}$ is equal to $10^{-4} \mathrm{~mol} \mathrm{l}^{-1}$ which is consistent with our other papers dealing with PE oxidation modeling. In addition, [UFEOOH $]_{0}$ was fixed at a value 100 times higher because of the possible unsaturated fatty ester pre-oxidation occurring during the impregnation phase. It has been shown previously that such values should be employed for simulating the $\mathrm{CL}$ curves of pure UFEs oxidation [14].

The system of differential equations established from the kinetic scheme is solved using the following initial conditions:

$$
\begin{array}{ll} 
& {\left[\mathrm{UFE}^{\circ}\right]_{0}=\left[\mathrm{UFEOO}^{\circ}\right]_{0}=\left[\mathrm{PE}^{\circ}\right]_{0}=\left[\mathrm{PEOO}^{\circ}\right]_{0}=0} \\
\text { At } t=0: & {[\mathrm{UFEOOH}]_{0}=10^{-2} \mathrm{~mol} \mathrm{l}^{-1}} \\
& {[\mathrm{PEOOH}]_{0}=10^{-4} \mathrm{~mol} \mathrm{l}^{-1}}
\end{array}
$$

For the sake of simplicity, the densities of the PE amorphous phase and the fatty esters are assumed to be the same so that:

$$
\begin{aligned}
& {[\mathrm{PEH}]_{0}=\frac{\rho_{\mathrm{PE}}^{\mathrm{a}}}{\mathrm{M}_{\mathrm{CH} 2}} \times\left(1-\mathrm{w}_{\mathrm{UFE}}^{\mathrm{eq}}\right)} \\
& {[\mathrm{UFEH}]_{0}=\frac{1}{1-\mathrm{x}_{\mathrm{C}}} \cdot \frac{\rho_{\mathrm{PE}}^{\mathrm{a}}}{\mathrm{M}_{\mathrm{UFE}}} \times\left(1-\mathrm{w}_{\mathrm{UFE}}^{\mathrm{eq}}\right) \times \mathrm{n}_{\mathrm{UFE}}}
\end{aligned}
$$

here:

- $\rho^{\mathrm{a}} \mathrm{PE}$ is the density of PE amorphous phase.

\begin{tabular}{|c|c|c|c|c|c|}
\hline Macroradical & Model compound & $\Delta \mathrm{H}_{\mathrm{f}}\left(\mathrm{kJ} \mathrm{mol}^{-1}\right)$ & $\Delta \mathrm{S}_{\mathrm{f}}\left(\mathrm{J} \mathrm{\textrm {mol } ^ { - 1 } \mathrm { K } ^ { - 1 } )}\right.$ & $\Delta \mathrm{H}_{\mathrm{f}}(423 \mathrm{~K})\left(\mathrm{kJ} \mathrm{mol}^{-1}\right)$ & $\Delta \mathrm{H}_{\mathrm{f}}(353 \mathrm{~K})\left(\mathrm{kJ} \mathrm{mol}^{-1}\right)$ \\
\hline $\begin{array}{c}-\mathrm{CH}_{2}-\underset{\mathrm{I}}{\mathrm{CH}}-\mathrm{CH}_{2}- \\
\mathrm{O}^{\circ}\end{array}$ & iso $-\mathrm{C}_{3} \mathrm{H}_{7}-\mathrm{O}^{\circ}$ & -75.3 & 355.3 & -225.6 & -202.8 \\
\hline $\begin{array}{c}-\mathrm{CH}=\mathrm{CH}-\underset{1}{\mathrm{CH}}-\mathrm{CH}_{2}- \\
\mathrm{OO}^{\circ}\end{array}$ & $\mathrm{H}_{2} \mathrm{C}=\mathrm{CH}-\mathrm{CH}_{2}-\mathrm{OO}^{\circ}$ & 96.3 & 350.3 & -51.6 & -27.4 \\
\hline $\begin{array}{c}-\mathrm{CH}_{2}-\underset{\mathrm{CH}}{\mathrm{C}}-\mathrm{CH}_{2}- \\
\mathrm{OO}^{\circ}\end{array}$ & iso $-\mathrm{C}_{3} \mathrm{H}_{7}-\mathrm{OO}^{\circ}$ & -46 & 345.3 & -192.1 & -168 \\
\hline $\begin{array}{c}-\mathrm{CH}=\mathrm{CH}-\underset{1}{\mathrm{CH}}-\mathrm{CH}_{2}- \\
\mathrm{O}^{\circ}\end{array}$ & 1 & 104.6 & 364.1 & -49.4 & -24 \\
\hline
\end{tabular}

- $\mathrm{M}_{\mathrm{CH} 2}$ is the molar mass of the methylene group since the PE repetitive structural unit holds an abstractable hydrogen.

Table 1

Calculation of free enthalpy changes for cross bimolecular hydroperoxide decomposition. 
- MUFE is the molar mass of the unsaturated fatty ester.

$-w^{e q}$ UFE is the weight fraction of UFE in the impregnated PE at the beginning of exposure.

- The $\left(1-x_{C}\right)$ factor expresses the fact that fatty ester is dissolved only in the PE amorphous phase.

- $n_{U F E}$ is the number of most abstractable hydrogens in the UFE. Here, in the frame of a first approach, only the more reactive hydrogen i.e.: $n_{\mathrm{UFE}}=2$ for allylic hydrogens in methyl oleate, and $n_{\mathrm{UFE}}=2$ for methylene in $\alpha$ of the two double bond positions in methyl linolenate, will be considered.

The numerical resolution of the kinetic model gives rise to the kinetic functions $\left[\mathrm{UFE}^{\circ}\right],\left[\mathrm{UFEOO}^{\circ}\right],[\mathrm{UFEOOH}],\left[\mathrm{PE}^{\circ}\right],\left[\mathrm{PEOO}^{\circ}\right]$, $[\mathrm{PEOOH}]$ which permits comparisons with the experimental results reported above.

Let us first consider CL emission. Several mechanisms have been proposed for $\mathrm{CL}$ emission. In the first, emission is from a $\mathrm{P}=\mathrm{O}^{*}$ generated from a Russel-type termination, which is in fact questionable because this reaction is not expected to occur in PP for which the CL intensity is, however, very high [23]. In a second mechanism, emission is from $\mathrm{P}=\mathrm{O}^{*}$ generated by $\beta$-scission of alkoxy: $-\mathrm{CH}_{2} \rightarrow \mathrm{C}-\mathrm{O}^{\circ} \rightarrow>\mathrm{C}=\mathrm{O}^{*}+-\mathrm{CH}_{2}{ }^{\circ}$ [24]. Emission from $\mathrm{O}_{2}{ }^{*}$ has also been proposed [25] as well as emission from a bimolecular POOH combination $[26,27]$.

The difference between all these mechanisms consists in the fact that the excited specie responsible for CL emission comes from either the initiation or termination reaction. It can be shown that the initiation rate varies pseudo linearly with the oxygen pressure while the termination rate varies linearly with the square of oxygen pressure [28]. This confirms that CL comes from the bimolecular decomposition of $\mathrm{POOH}[28,29]$. This conclusion is in good agreement with the majority of literature reports as well as being based on other reasoning $[26,27]$. Here, it can be assumed that:

$\mathrm{I}_{\mathrm{CL}}=\Phi \times \mathrm{k}_{\mathrm{b}} \cdot[\mathrm{POOH}]^{2}$

It should be noted that it is easy to verify that the shape of simulated curve remains almost the same by making the assumption that $\mathrm{CL}$ comes from $\mathrm{POOH}+\mathrm{POOH} \rightarrow \ldots$ or from $\mathrm{POO}^{\circ}+\mathrm{POO}^{\circ} \rightarrow \ldots$.

In the absence of any other useful information, it will be assumed that $\Phi$ is independant of the structure. The chemiluminescence intensity can therefore be expressed as:

$$
\begin{aligned}
\mathrm{I}_{\mathrm{CL}}= & \Phi \times\left(\mathrm{k}_{\mathrm{b} 11} \cdot[\mathrm{UFEOOH}]^{2}+\mathrm{k}_{\mathrm{b} 12} \cdot[\mathrm{UFEOOH}] \cdot[\mathrm{PEOOH}]\right. \\
& \left.+\mathrm{k}_{\mathrm{b} 22} \cdot[\mathrm{PEOOH}]^{2}\right)
\end{aligned}
$$

Next, we will consider the carbonyl buildup. Carbonyl concentration is calculated as a post treatment of model by:

$$
\begin{aligned}
\frac{\mathrm{d}[\mathrm{PE}=\mathrm{O}]}{\mathrm{dt}}= & \left(1-\mathrm{x}_{\mathrm{C}}\right) \cdot \gamma_{\mathrm{CO}} \cdot\left(\mathrm{k}_{\mathrm{u} 2}[\mathrm{PEOOH}]+\mathrm{k}_{\mathrm{b} 22}[\mathrm{PEOOH}]^{2}\right. \\
& \left.+\mathrm{k}_{\mathrm{b} 12}[\mathrm{PEOOH}][\mathrm{UFEOOH}]+\mathrm{k}_{622}\left[\mathrm{PEOO}^{\circ}\right]^{2}\right)
\end{aligned}
$$

$\frac{\mathrm{d}[\mathrm{UFE}=\mathrm{O}]}{\mathrm{dt}}=\left(1-\mathrm{x}_{\mathrm{C}}\right) \cdot \mathrm{k}_{\mathrm{b} 11}[\mathrm{POOH}]^{2}$

here, the term $\left(1-x_{C}\right)$ expresses the fact that oxidation occurs only in the PE amorphous phase. The term $\gamma_{\mathrm{CO}}$ is the carbonyl yield for alkoxy decomposition [5]. In UFE, there is also carbonyl formation with a yield certainly lower than 1 . But in the present study for the sake of simplicity, this is arbitrarily fixed as unity.
Table 3

Rates constants for methyl ester oxidation and cross propagation reactions (values between brackets correspond to expected values from Ref. [14] or values from $\mathrm{k}_{321}=\mathrm{k}_{311}$ and $\mathrm{k}_{312}=\mathrm{k}_{322}$.

\begin{tabular}{llllllll}
\hline & & $\mathrm{k}_{\mathrm{b} 11}$ & $\mathrm{k}_{21}$ & $\mathrm{k}_{311}$ & $\mathrm{k}_{611}$ & $\mathrm{k}_{312}$ & $\mathrm{k}_{321}$ \\
\hline $150{ }^{\circ} \mathrm{C}$ & $\mathrm{O}$ & $2 \times 10^{-3}$ & $10^{7}$ & 131 & $10^{8}$ & 11 & 131 \\
& & $\left(1.9 \times 10^{-3}\right)$ & $\left(10^{7}\right)$ & $(131)$ & $\left(4.510^{8}\right)$ & $(11)$ & $(131)$ \\
& LNO & $1.25 \times 10^{-2}$ & $10^{7}$ & 525 & $4.510^{8}$ & 0.25 & 525 \\
$80{ }^{\circ} \mathrm{C}$ & & $\left(1.25 \times 10^{-2}\right)$ & $\left(10^{7}\right)$ & $(525)$ & $\left(3.510^{9}\right)$ & $(11)$ & $(525)$ \\
& \multirow{2}{*}{$\mathrm{O}$} & $5 \times 10^{-6}$ & $10^{7}$ & 9.25 & $2.010^{7}$ & 0.24 & 9.25 \\
& & $\left(4.5 \times 10^{-6}\right)$ & $\left(10^{7}\right)$ & $(9.25)$ & $\left(2.010^{7}\right)$ & 0.24 & $(9.25)$ \\
& & $4 \times 10^{-5}$ & $10^{7}$ & 92 & $2.010^{8}$ & 0.12 & 92 \\
& & $\left(4 \times 10^{-5}\right)$ & $\left(10^{7}\right)$ & $(92)$ & $\left(2.010^{8}\right)$ & $(0.24)$ & $(92)$ \\
\hline
\end{tabular}

It should also be noted that some carbonyls can also be generated as a result of termination in an UFE self-oxidation process. But in the absence of quantitative information, this process will be neglected. By neglecting some minor terms, the following can be written:

$$
\begin{aligned}
\frac{\mathrm{d}[\mathrm{PE}=\mathrm{O}]}{\mathrm{dt}} & +\frac{\mathrm{d}[\mathrm{UFE}=\mathrm{O}]}{\mathrm{dt}} \propto\left\{\mathrm{k}_{\mathrm{b} 11}[\mathrm{UFEOOH}]^{2}+\mathrm{k}_{\mathrm{b} 22}[\mathrm{PEOOH}]^{2}\right. \\
& \left.+\mathrm{k}_{\mathrm{b} 12}[\mathrm{UFEOOH}][\mathrm{PEOOH}]\right\}
\end{aligned}
$$

Thus : $\quad \frac{\mathrm{d}[\text { carbonyls }]}{\mathrm{dt}} \propto \mathrm{I}_{\mathrm{CL}}$

It is not surprising, therefore, to discover that the rate of carbonyl buildup varies in the same way with time as the CL intensity. Using the rate constants given in Table 3, the modeling runs gave rise to the following data:

A fair simulation of CL curve shape was found as shown in Fig. 6. The model permits a better understanding of the course of the oxidation as shown in Fig. 7. Here, the shift of the induction period duration relative to $\mathrm{PE}$ is shown when $\mathrm{PE}$ is oxidized in presence of UFE.

Acceptable simulations for carbonyl build-up curves are seen from the results shown in Figs. 4 and 5. Their shape is in reasonable agreement with the experimental data. Taking into consideration the relative complexity for analyzing FTIR spectra in the carbonyl region and the corresponding kinetic curves, this agreement cannot be a simple coincidence. The simulations of the oxidation state of the matrix (i.e. the concentration in carbonyl hold by PE chains) are acceptable (Figs. 4 and 5). Of particular note is the fact that methyl ester accelerates the course of the PE

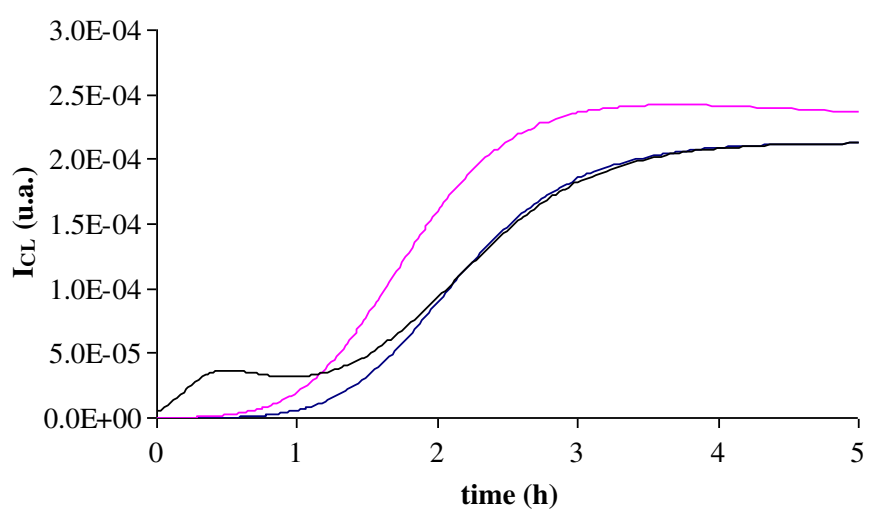

Fig. 6. Simulations of normalized CL curves at $150^{\circ} \mathrm{C}$ using kinetic parameters given in Tables 2 and 3. 

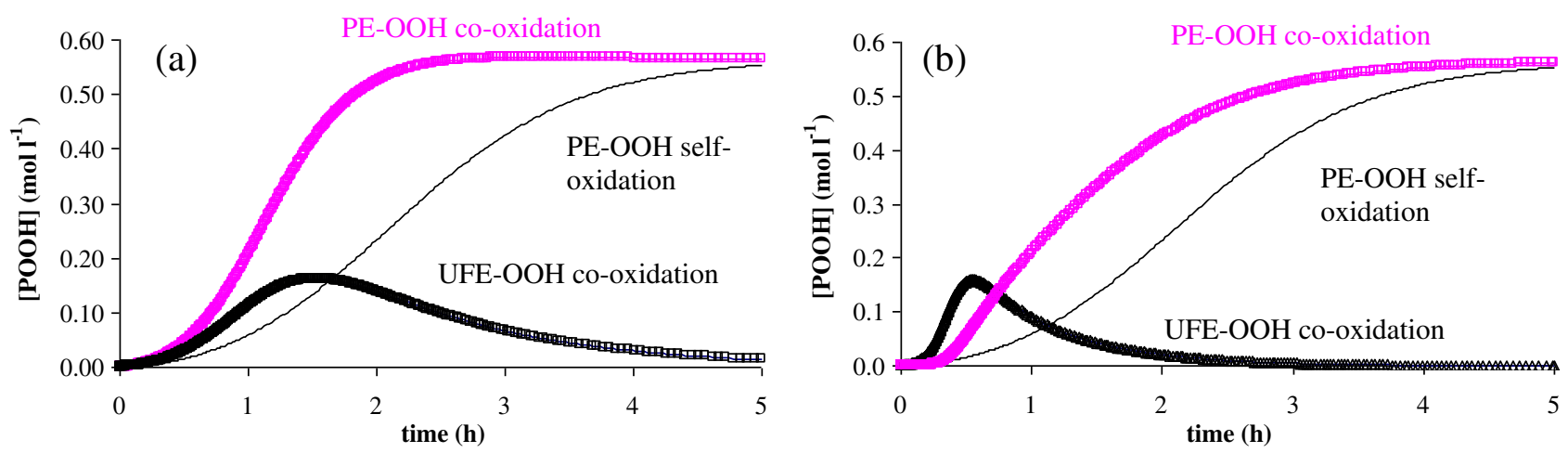

Fig. 7. Simulations of kinetic curves for PEOOH and UFEOOH for methyl oleate (a) and linolenate (b) using kinetic parameters given in Tables 2 and 3.

oxidation compared to when PE is oxidized alone. The model also describes the influence on the PE oxidation kinetics of increasing the methyl ester concentration in the PE amorphous phase. These results are shown in Fig. 4.

Finally, the rate constants for methyl esters are found to be relatively very close or even identical to those determined from the corresponding self-oxidation studies [14]. One minor discrepancy is observed for one termination constant (Table 3 ). It could actually be envisaged that the rate constant $\mathrm{k}_{611}$ is equal to the one determined in the case of methyl ester self-oxidation. But the rate constants for cross termination $\mathrm{k}_{612}$ would have a different value, actually lower than the geometric average $\left(\mathrm{k}_{611} \mathrm{k}_{622}\right)^{1 / 2}$. In fact, given all the possible sources of error such as the differences in the methyl ester purity between this work and [14], or differences in polarity between the pure UFE medium the PE matrix, the numerous simplifying hypotheses used for the rate constant determination [14], then there is really rather a good agreement between the constants used here for simulating the cooxidation curves and those used for simulating the CL curves for the oxidation of pure methyl esters. Even if the hypothesis of geometric means is considered questionable, it seems that it can still offer a rough estimation of the unknown rate constants for some cross reactions.

\section{Conclusions}

The kinetics of the thermal oxidation of PE combined with different unsaturated fatty esters was studied using chemiluminescence in PE molten state and by FTIR in the PE solid state. It was observed that these unsaturated molecules oxidize faster than PE and hence their addition to PE accelerates its degradation. This effect is attributed to the transfer of radical sites from UFE to the PE. A kinetic model for co-oxidation has been shown to simulate the main experimental trends. The model used kinetics parameters employed for modeling PE and UFE self-oxidation. Simulations can successfully be compared with the chemiluminescence results obtained for both oxidation in molten state $\left(150{ }^{\circ} \mathrm{C}\right)$ as well as in the solid state $\left(80^{\circ} \mathrm{C}\right)$. Finally, both reactant oxidation by-products were successfully quantified.

\section{Acknowledgments}

This work was carried out within the frame of the "contract "BioCarbMat" and sponsored by the competitivity pole MOV'EO. This fact is gratefully acknowledged. ER thanks the staff of Bratislava Polymer Institute for his productive and pleasant stay.

\section{References}

[1] Tobolsky AV, Metz DJ, Mesrobian RB. Low temperature autoxidation of hydrocarbons: the phenomenon of maximum rates. J Am Chem Soc 1950;72(5): 1942-52.

[2] Audouin L, Gueguen V, Tcharkhtchi A, Verdu J. Close loop mechanistic schemes for hydrocarbon polymer oxidation. J Polym Sci A: Polym Chem 1995;33(6): 921-7.

[3] Korcek S, Chenier JHB, Howard JA, Ingold KU. Absolute rate constants for hydrocarbon auto-oxidation-activation energies for propagation ad the correlation of propagation rate constants. Can J Chem 1972;50(14): 2285-97.

[4] Richaud E, Farcas F, Bartoloméo P, Fayolle B, Audouin L, Verdu J. Effect of oxygen pressure on the oxidation kinetics of unstabilised polypropylene. Polym Degrad Stab 2006;91(2):398-405.

[5] Khelidj N, Colin X, Audouin L, Verdu J, Monchy-Leroy C, Prunier V. Oxidation of polyethylene under irradiation at low temperature and low dose rate. Part II. Low temperature thermal oxidation. Polym Degrad Stab 2006; 91(7):1598-605.

[6] Coquillat M, Verdu J, Colin X, Audouin L, Nevière R. Thermal oxidation of polybutadiene. Part 2: mechanistic and kinetic schemes for additivefree non-crosslinked polybutadiene. Polym Degrad Stab 2007;92(7): 1334-42.

[7] Broska R, Rychly J, Csomorova K. Carboxylic acid assisted oxidation of polypropylene studied by chemiluminescence. Polym Degrad Stab 1999;63(2): 231-6.

[8] Gutiérrez G, Fayolle F, Régnier G, Medina J. Thermal oxidation of claynanoreinforced polypropylene. Polym Degrad Stab 2010;95:1708-15.

[9] Decker C, Mayo FR, Richardson H. Aging and degradation of polyolefins. III Polyethylene and ethylene-propylene copolymers. J Polym Sci Polym Chem Ed 1973;11(11):2879-98.

[10] Russell GA. The competitive oxidation of cumene and tetralin. J Am Chem Soc 1955;77(7):4583-90.

[11] Broska R, Billingham NC, Fearon PK. Accelerating effect of poly(methyl methacrylate) on rubber oxidation, part 1: a chemiluminescence study. Polym Degrad Stab 2008;93(6):1100-8.

[12] Colin X, Richaud E, Verdu J, Monchy-Leroy C. Kinetic modelling of radiochemical aging of ethylene-propylene copolymers. Rad Phys Chem 2010; 79(3):365-70.

[13] Maru MM, Lucchese MM, Legnani C, Quirino WG, Balbo A, Bulhões Aranha I, et al. Biodiesel compatibility with carbon steel and HDPE parts. Fuel Proc Tech 2009;90(9):1175-82.

[14] Richaud E, Audouin L, Fayolle B, Verdu J, Matisová-Rychlá L, Rychlý J. Rate constants of oxidation of unsaturated fatty esters studied by chemiluminescence. Chem Phys Lipids 2012;165(7):753-9.

[15] Demirbas A. Biodiesel fuels from vegetable oils via catalytic and non-catalytic supercritical alcohol transesterifications and other methods: a survey. Energ Convers Manag 2003;44(13):2093-109.

[16] Richaud E, Flaconnèche B, Verdu J. Biodiesel permeability in polyethylene. Polym Test 2012;31(8):1070-6.

[17] Rugg FM, Smith JJ, Bacon RC. Infrared spectrophotometric studies on polyethylene. II. Oxidation. J Polym Sci 1954;13(72):535-47.

[18] Broska R, Rychlý J. Double stage oxidation of polyethylene as measured by chemiluminescence. Polym Degrad Stab 2001;72(2):271-8.

[19] Carlsson DJ, Brousseau R, Zhang C, Wiles DM. Polyolefin oxidation: quantification of alcohol and hydroperoxide products by nitric oxide reactions. Polym Degrad Stab 1987;17(4):303-18.

[20] Lacoste J, Vaillant D, Carlsson DJ. Gamma-, photo-, and thermally-initiated oxidation of isotactic polypropylene. J Polym Sci A: Polym Chem 1993; 31(3):715-22.

[21] Van Krevelen DW, Te Nijenhuis K. Properties of polymers, their correlation with chemical structure; their numerical estimation and prediction from 
additive group contributions. 4th ed. Amsterdam: Elsevier; 2009 [Chapter 18] p. 655-702.

[22] Richaud E, Colin X, Fayolle B, Audouin L, Verdu J. Induction period in the lowtemperature thermal oxidation of saturated hydrocarbons: example of polyethylene. Int J Chem Kinet 2008;40(12):769-77.

[23] Matisová-Rychlá L, Rychlý J, Slovák K. Effect of the polymer type and experimental parameters on chemiluminescence curves of selected materials. Polym Degrad Stab 2003;82(2):173-80.

[24] Audouin-Jirackova L, Verdu J. Chemiluminescence of hydrocarbon polymers. J Polym Sci Part A: Polym Chem 1987;25(5):1205-15.

[25] Harada Y, Suzuki K, Hashimoto M, Tsukagoshi K, Kimoto H. Chemiluminescence from singlet oxygen that was detected at two wavelengths and effects of biomolecules on it. Talanta 2009;77(3):1223-7.
[26] Billingham NC, Grigg MN. The kinetic order of decomposition of polymer hydroperoxides assessed by chemiluminescence. Polym Degrad Stab 2004; 83(3):441-51.

[27] Kron A, Stenberg B, Reitberger T, Billingham NC. Chemiluminescence from oxidation of polypropylene: correlation with peroxide concentration. Polym Degrad Stab 1996;53(1):119-27.

[28] Verdu J, Colin X, Audouin L, Rychly J, Matisová-Rychlá M. Chemiluminescence from the thermal oxidation of polyisoprene and polybutadiene I. Influence of oxygen pressure on the chemiluminescence of polyisoprene during its oxidation. Polym Degrad Stab 2006;91(6):1387-94.

[29] Achimsky L, Audouin L, Verdu J, Rychlá L, Rychlý J. The effect of oxygen pressure on the rate of polypropylene oxidation determined by chemiluminescence. Eur Polym J 1999;35(4):557-63. 